\title{
The path to eradication: a progress report on the malaria-eliminating countries
}

Gretchen Newby, MSPH $^{1}$

Adam Bennett, $\mathrm{PhD}^{1}$

Erika Larson, $\mathrm{MSc}^{1}$

Chris Cotter, $\mathrm{MPH}^{1}$

Rima Shretta, $\mathrm{MSc}^{1}$

Allison A. Phillips, BA ${ }^{1}$

Sir Richard G.A. Feachem, DSc(Med) ${ }^{1}$

${ }^{1}$ Global Health Group, University of California, San Francisco, $55016^{\text {th }}$ St, $3^{\text {rd }}$ Floor, San Francisco, CA 94158, USA

Correspondence to:

Gretchen Newby

UCSF Global Health Sciences

Mission Hall, Box 1224

$55016^{\text {th }}$ St, $3^{\text {rd }}$ Floor

San Francisco, CA 94158

$+1.415 .476 .5649$

gretchen.newby@ucsf.edu

Abstract word count: 251

Body of paper word count: 4,511 


\begin{abstract}
In the past several years, as worldwide morbidity and mortality due to malaria have continued to decline, the global malaria community has grown increasingly supportive of the idea of malaria eradication. In 2015, three noteworthy global documents were released - the World Health Organization's Global Technical Strategy for Malaria 2016-2030, the Roll Back Malaria Partnership’s Action and Investment to defeat Malaria 2016-2030, and From Aspiration to Action: What Will It Take to End Malaria?- that collectively advocate for malaria elimination and eradication and outline key operational, technical, and financial strategies to achieve progress toward malaria eradication. In light of this remarkable paradigm shift in global attitudes toward malaria elimination and eradication, and as the malaria community debates how and when to embark on this ambitious goal, it is important to assess current progress along the path to eradication. Although low-income, high-burden countries are often the focus when discussing the significant challenges of eradication, the progress toward elimination in middle-income, low-burden countries is a major driver of global progress and deserves better recognition. In addition, while global support and guidance is essential for success, malaria elimination and eradication efforts will ultimately be driven at the country level and achieved in a collaborative manner, region by region. In this paper, we examine the current status of the 35 malaria-eliminating countries, summarise existing national and regional elimination goals and the regional frameworks that support them, and identify the most significant enabling factors and potential barriers to achieving eradication by a theoretical end date of 2040.
\end{abstract}




\section{Introduction}

For decades after the conclusion of the World Health Organization's (WHO) mid-20 ${ }^{\text {th }}$ century Global Malaria Eradication Programme (GMEP), a strategy of malaria eradication was no longer prioritized and the accepted global approach was one of sustained control. After the launch of the Roll Back Malaria Initiative (RBM) in 1998, the Millennium Development Goals in 2000, and the formation of new donor mechanisms including the Global Fund to Fight AIDS, Tuberculosis and Malaria (Global Fund) in 2002 and the United States President's Malaria Initiative in 2005, global malaria morbidity and mortality began to decline. This was accelerated by the development and scale-up of innovative tools and effective control strategies and the unprecedented political and financial commitment from malaria-endemic countries. In 2007, in light of this extraordinary progress, Bill and Melinda Gates called for a renewed commitment to eradicate malaria. ${ }^{1}$ Endorsed by the WHO Director-General and supported by nations and organizations throughout the malaria community, the push for national and regional malaria elimination quickly built momentum and the countries and regions already implementing elimination plans were given due recognition..$^{2-4}$ A three-part strategy for eradication under the Global Malaria Action Plan (GMAP) (see Webappendix) was developed by RBM, a rapidly growing number of countries set forth national elimination goals, and regional networks were formed to facilitate collaboration and bolster political and financial support for countries pursuing elimination. ${ }^{5-10}$

Elimination is now considered an attainable goal by most national malaria programs, and the idea of eradication is once again on the global health agenda. Over 100 countries have eliminated malaria in the past century. Between 2007 and 2013, four countries were certified as malaria-free by WHO (Armenia, Morocco, Turkmenistan, United Arab Emirates), an additional eight countries moved into the WHO’s prevention of reintroduction phase after sustaining at least three years of zero local malaria transmission (Argentina, Egypt, Iraq, Georgia, Kyrgyzstan, Oman, Syrian Arab Republic, Uzbekistan), and five others interrupted local transmission (Azerbaijan, Costa Rica, Paraguay, Sri Lanka, Turkey). ${ }^{11}$ The malaria map continues to shrink with global economic development and increasing political and financial support for elimination, and the toolkit of innovative technologies and interventions to defeat malaria continues to expand. $^{12}$

This incredible progress, achieved in just seven years, prompted Bill Gates to once again make a bold declaration in November 2014: not only can malaria be eradicated, it can be achieved within a generation. ${ }^{13}$ As the global malaria community debates how and when to embark on this ambitious and aggressive eradication goal, articulating the great achievements made to date and elucidating the top priorities, challenges, and gaps will help inform these endeavours. In previous articles published in The Lancet in 2010 and 2013, respectively, we described the concepts and rationale behind malaria elimination from operational, technical, and financial standpoints, as well as the evolving epidemiological

complexity of countries in low transmission settings. ${ }^{6,14-17}$ As a continuation of that work, we present here the current status of the 35 malaria-eliminating countries, summarise existing national and regional elimination goals and the regional frameworks that support them, and identify the most significant enabling factors and potential barriers to achieving eradication by a theoretical end date of 2040 .

\section{The 35 malaria-eliminating countries}

Today, in 2015, there are currently 35 countries that meet the malaria-eliminating criteria (Figure 1 and Webappendix), with national or regional elimination goals ranging from 2013 to 2035. ${ }^{6,14,18}$ The majority 
are aiming to achieve elimination by 2020. From 2000 through 2013, these 35 countries reduced their malaria burden by a remarkable 90 percent, from 1.6 million reported cases down to 160,000, and reported deaths due to malaria have declined by 87 percent (Figure 2). The trends observed in the malariaeliminating countries are particularly impressive when compared to the 30 percent and 47 percent declines in global malaria morbidity and mortality, respectively, between 2000 and $2013 .{ }^{11}$

Three countries-Argentina, Kyrgyzstan, and Uzbekistan - were recently removed from the malariaeliminating country list after achieving three consecutive years of zero local malaria transmission, WHO's criteria for the prevention of reintroduction phase. ${ }^{19}$ Argentina and Kyrgyzstan have initiated the process of malaria-free certification with WHO, as has Paraguay, an eliminating country which reached the threeyear mark of zero locally transmitted cases in October 2014 (see Webappendix). ${ }^{11,20}$ Sri Lanka, which reported its last local case in 2012, reached the three-year mark in October 2015. ${ }^{21}$ Three other countries have achieved zero local transmission but have not yet sustained it for three consecutive years: Azerbaijan, which reported zero cases for the first time in 2013; and Costa Rica and Turkey, both of which reported local malaria cases in 2013 and 2014, but upon investigation, all cases were determined to be relapsing Plasmodium vivax infections acquired in previous years. ${ }^{11,22-23}$ These three countries met their elimination goals; notably, Costa Rica beat its national goal of 2020 by seven years.

The other 30 malaria-eliminating countries have made tremendous progress toward their elimination goals (Figure 3). In 2013, eight countries reported fewer than 50 locally transmitted cases (Algeria, Belize, Bhutan, Cape Verde, El Salvador, Mayotte, Saudi Arabia, Tajikistan); all but Mayotte have stated goals of elimination by 2020. Eight additional countries reported fewer than 800 cases (Botswana, China, Dominican Republic, Iran, Mexico, Panama, Republic of Korea, Swaziland), and have set elimination goals ranging from 2017 to $2025 .{ }^{11,18}$ Based on current epidemiological status and recent trends, many of these sixteen countries will achieve their stated elimination goals early. The remaining 14 malariaeliminating countries continue to make steady progress.

Despite their impressive achievements, the 35 malaria-eliminating countries face significant challenges, and some have struggled to sustain their gains. Solomon Islands and Vanuatu are examples of lower middle-income island nations that have had difficulty maintaining robust malaria-elimination programs in recent years. As a result of weak program capacity, both countries have experienced periodic spikes in cases that have proven challenging to bring under control. Sustaining domestic and international funding as malaria burden declines is a serious concern for most of the eliminating countries, 15 of which are now upper-middle income and are no longer eligible for the donor funding that supported their transition from control to elimination. ${ }^{24}$

Another major challenge for the 35 malaria-eliminating countries is the threat of malaria importation. ${ }^{25}$ For example, four countries in southern Africa_-Botswana, Namibia, South Africa, and Swaziland-are seeking to eliminate local transmission within the next five years, but many of their neighbours have much higher malaria burdens. Mobile and migrant populations moving across their borders often serve as primary sources of imported malaria cases, which are likely to drive secondary transmission. ${ }^{26,27}$ These four malaria-eliminating countries all experienced increases in cases and deaths between 2012 and 2013, possibly arising from imported malaria. Importation from higher endemic neighbours is a common challenge across most of the 35 malaria-eliminating countries; many that have reduced local transmission since 2000 have also seen increases in imported cases. 


\section{Regional initiatives and progress toward elimination goals}

Regional collaboration has been a key driver of progress for the 35 malaria-eliminating countries. Regional malaria elimination initiatives have facilitated the coordination of interventions, the sharing of surveillance and coverage data, allowed for strengthened communication and knowledge-transfer among countries facing common problems, and helped generate much-needed political pressure on governments to increase support for malaria elimination. In recent years, multi-country collaboration has been formalised under several regional initiatives, some of which have set ambitious regional elimination goals (see Webappendix). In some regions, Mesoamerica for example, the regional goal is more aggressive than milestones individual member nations had previously targeted, serving to push countries toward elimination faster than if they carried on alone. In regions that are inclusive of countries still in the control phase, such as Asia Pacific, the regional goal is more conservative than many of the national goals, which may serve to encourage countries with high transmission to catch up with their neighbours that are nearing elimination (Figure 4).

Two early regional elimination initiatives were launched in the mid-2000s with regional elimination goals of 2015. The WHO-EURO initiative was formalised in 2005 under the Tashkent Declaration. ${ }^{7}$ Six of the nine signatory countries-Armenia, Georgia, Kazakhstan, Kyrgyzstan, Turkmenistan, and Uzbekistanhave moved into the prevention of reintroduction phase, while three-Azerbaijan, Tajikistan, and Turkey-remain in the elimination phase. In 2014, only two local cases were reported throughout the entire EURO region, both in Tajikistan. ${ }^{22}$ However, about 5,000 imported cases were reported in the region - largely from Pakistan, India, and Afghanistan — indicating the need to maintain regional collaboration to prevent the re-establishment of local transmission through active surveillance and crossborder coordination with other EURO countries, as well as neighbouring countries in the Eastern Mediterranean region (EMRO) and the South-East Asian region (SEARO). ${ }^{28}$ No local cases have been reported in the EURO region as of September 2015. ${ }^{29}$

The Malaria-Free Arabian Peninsula initiative focused on the two peninsular countries with continued transmission, Saudi Arabia and Yemen, and prioritised cross-border coordination of surveillance and vector control activities. Extensive financial support for Yemen was provided by Gulf Cooperation Council member countries. ${ }^{8}$ While escalating political instability in Yemen has prevented the country from improving its malaria situation, Saudi Arabia reported only 34 local cases in 2013. ${ }^{11,30}$

In the Asia Pacific region, several regional bodies support malaria elimination. The first, the Asia Pacific Malaria Elimination Network (APMEN), was launched in 2009 as a network of countries, institutions, and stakeholders working together to eliminate malaria by facilitating collaboration and knowledge sharing, conducting training and research, increasing malaria program capacity and leadership, and building the evidence base for a regional elimination framework. ${ }^{31}$ In the past six years, eight countries have joined the original ten country partners of APMEN, the most recent of which was Papua New Guinea in September 2015. ${ }^{32}$ Participation in APMEN helps countries progress toward elimination by providing a forum to discuss programmatic and technical challenges and successes. ${ }^{9,33}$ For example, after learning of China's successful implementation of a rigorous surveillance and response system, other APMEN country partners have adopted the same approach. ${ }^{34}$

APMEN works in tandem with the Asia Pacific Leaders Malaria Alliance (APLMA), an affiliation of heads of government formed in 2013 to accelerate progress toward regional elimination in 22 countries. Under the guidance of APLMA's co-chairs, regional leaders endorsed a goal of a malaria-free Asia 
Pacific by 2030 at the East Asia Summit in 2014..$^{35,36}$ APLMA’s strategic roadmap for malaria elimination, finalised in November 2015, emphasises aggressive, evidence-based responses to artemisinin and insecticide resistance, support for vulnerable and hard-to-reach groups, and the generation of new and innovative financing streams to address the growing funding gap for eliminating countries. ${ }^{37}$

The 2030 malaria-free Asia Pacific goal is further supported by the WHO’s Strategy for Malaria Elimination in the Greater Mekong Subregion, which includes Cambodia, Lao People's Democratic Republic (PDR), Myanmar, Thailand, Vietnam, and China's Yunnan Province. ${ }^{38}$ In light of the serious threat of Plasmodium falciparum resistance to artemisinin and the potential for it to spread to India and Africa, merely containing resistance has been deemed insufficient; elimination of regional $P$. falciparum transmission is recognised as the only acceptable response to this threat. ${ }^{38,39}$ The strategy outlines a phased approach to elimination, with $P$. falciparum transmission eliminated in all six countries by 2025, and all forms of malaria eliminated by 2030. These efforts are supported, in part, by the Regional Artemisinin Initiative grant from the Global Fund, which has allocated US \$100 million over three years to halt the spread of artemisinin resistance. ${ }^{38,40}$

In southern Africa, malaria elimination is supported by the E8 initiative, launched in 2009 to push the region toward zero malaria transmission. Coordinated by the E8 Secretariat, the initiative facilitates collaboration and data-sharing across four malaria-eliminating countries at the frontline-Botswana, Namibia, South Africa, and Swaziland — and their second line northern neighbours working to reduce transmission and achieve subnational elimination-Angola, Mozambique, Zambia, and Zimbabwe. The frontline countries are seeking to achieve elimination by 2020, a goal that is highly dependent upon strong cross-border coordination with the second line countries. ${ }^{27,41}$ The E8 was recently awarded a three-year grant from the Global Fund to support regional surveillance activities, including the development of a shared surveillance system to track regional case trends in real time, the formation of malaria health posts in areas with poor access to healthcare, and deployment of rapid response teams along national borders. $^{27,41}$

The African Leaders Malaria Alliance (ALMA) - a high-level coalition of 49 African Heads of Government-recently adopted the malaria elimination agenda and developed the 2030 Africa Malaria Elimination Scorecard to monitor and encourage progress across member nations. The African Union further endorsed this goal by calling for malaria elimination in Africa by $2030 .{ }^{42}$

Ten member countries of the Council of Health Ministers from Central America and the Dominican Republic recently joined an initiative to eliminate malaria by $2020 .^{43}$ The initiative is receiving financial support through a grant from the Global Fund entitled Elimination of Malaria in Mesoamerica and Hispaniola (EMMIE), a performance-based, cash-on-delivery model designed to catalyse action toward elimination. The launch of EMMIE has driven some of the participating countries to reorient their malaria programs to elimination, and led others to accelerate the elimination plans already in place to reflect the regional 2020 goal. ${ }^{43,44}$ Additional assistance for malaria elimination on Hispaniola by 2020 comes from a new consortium called Malaria Zero, which is assisting Haiti and Dominican Republic in the development and implementation of a collaborative elimination strategy. 45,46

\section{Global strategies and progress toward elimination/eradication goals}

The push to eliminate malaria has typically been a country's decision, often inspired by national reductions in burden, increased political commitment, and a readiness to take on the ambitious task. As 
more countries and regions are setting goals to eliminate, global donors and multinational agencies have grown increasingly supportive of the elimination agenda. Unwavering support at all levels—national, regional, and global — is essential to achieve malaria eradication, and global endorsement of the eradication agenda will help generate the leadership and guidance necessary for countries to strengthen their national programs.

RBM’s Action and Investment to Defeat Malaria 2016-2030 (AIM) and WHO’s Global Technical Strategy for Malaria 2016-2030 (GTS) both support the idea of elimination and eradication, stating that by 2020, malaria elimination will be achieved in at least ten countries that had transmission in 2015, and by 2030, elimination will be achieved in at least 35 countries, with an overall reduction in global malaria burden by 90 percent compared to 2015. ${ }^{47,48}$ Endorsed at the World Health Assembly in May 2015, the GTS serves as the technical basis for national malaria strategic plans. AIM, the second generation of the GMAP and launched in July 2015, serves as a global advocacy tool to ensure continued commitment and investment in malaria elimination and eradication, and positions malaria elimination as both benefiting from and contributing to the Sustainable Development Goals.

While the GTS and AIM support progressive elimination, a new global advocacy document, From Aspiration to Action: What Will It Take to End Malaria? seeks to revitalise a robust debate on global malaria eradication. Addressed to country leaders, global policy makers, donor countries, and partner institutions, From Aspiration to Action uses a theoretical eradication date of 2040 to anticipate what will be required in mobilizing resources, developing new tools and technologies, and implementing strategies to achieve a malaria-free world. The advocacy document also calls on the World Health Assembly to pass a resolution by 2020 , committing to a goal of global malaria eradication. ${ }^{18}$

With the growing global enthusiasm for eradication, the targets set by GTS and AIM are likely more conservative than what is needed to achieve the theoretical 2040 eradication goal described in From Aspiration to Action. The trajectories these documents set for the next fifteen years are quite cautious, putting the onus on the malaria community to make up tremendous ground in the final ten years (2030 to 2040) leading to eradication. Based on recent trends in epidemiology, funding, and political support, and taking into account the existing national and regional elimination goals, we project that up to 25 countries with transmission in 2015 can eliminate by 2020, and over 60 countries can eliminate by 2030, compared to the ten and 35, respectively, described in GTS and AIM (Figure 5).

\section{Enabling factors for achieving malaria eradication}

The announcement of a global eradication goal is likely to elevate the visibility and importance of malaria elimination, potentially inspiring new donors and stakeholders to lend financial, technical, and innovative operational support. While countries will face significant challenges as they pursue elimination, there are several factors that will further bolster global progress toward malaria eradication.

Identifying the most effective mix of interventions and strategies that programs can use for malaria elimination and empowering program managers to select the most appropriate combination of tools for implementation in their unique settings are key for success. Elimination requires a more nuanced approach to intervention choice beyond traditional vector control and case management that must be tailored to suit the local eco-epidemiology. Within a country, different provinces or districts may employ a wide variety of tools depending on the local vector, parasite, importation rates, and, most importantly, the behavioural profile of the target human population. Donors that finance malaria elimination and 
eradication efforts must support low-transmission programs in selecting and funding locally-appropriate interventions, and in providing flexible management, capacity building, and leadership training for a cadre of surveillance and response officers who can guide their programs toward interruption of malaria transmission. ${ }^{49}$ Appropriate intervention selection and strategy development for elimination hinges upon a rigorous, ongoing process of scientific research, knowledge sharing, and monitoring and evaluation. The Malaria Eradication Research Agenda (malERA) initiative and the Malaria Eradication Scientific Alliance have supported these efforts since 2008..$^{50,51}$

Low transmission settings present an opportunity to achieve malaria elimination, yet as cases decline in number, they tend to become clustered in geographic locations and among specific population groups, identification of which presents new operational challenges. ${ }^{15}$ For an elimination program, a strong surveillance system must enable the identification and classification of all foci of transmission and the targeting of appropriate resources and interventions in an aggressive and timely fashion. New surveillance tools such as spatial decision support systems (SDSS) that are linked to GPS-enabled smartphones and tablets or automated maps of transmission risk can support the identification and classification of hotspots, facilitate a rapid flow of data between levels of the health system, and generate real-time evidence to support the national program in choosing interventions and targeting limited resources. ${ }^{52,53}$ The WHO recently published a series of toolkits to improve access to high-risk migrant and mobile populations in the Greater Mekong Subregion, better detect population movement and new malaria transmission foci, and strengthen surveillance and epidemic response to drug-resistant malaria parasites. ${ }^{54}$ Similarly, methods for characterizing high-risk populations and understanding and monitoring their behaviors and movements are increasingly being adapted from the HIV field, which will allow malaria programs to appropriately tailor interventions to those population groups most at risk for infection. ${ }^{55}$

Malaria elimination is a regional and global public good: as more countries eliminate malaria within their borders, the risk that they will export malaria to their neighbours is reduced, better enabling the next wave of countries to embark on their own elimination plans. As regional initiatives grow in number and scope, surveillance platforms that capture early signs of drug and insecticide resistance as well as population movement and regional hotspots of transmission, such as that under development for the E8, will enable cross-border data sharing and regional-level responses. Further, these improvements to surveillance and regional collaboration also serve to strengthen the overall health systems of malaria-eliminating countries and will likely benefit the control, elimination, and eradication efforts of other diseases in the future.

Finally, advocacy plays an essential role in bolstering political and financial support for malaria elimination. Key advocacy elements that have been identified as critical factors in infectious disease elimination are under development, including core advocacy messages, provision of advocacy tools, strong partnership-building, construction of a business case, and community engagement. ${ }^{56}$ With the increasing focus on domestic financing mobilization, these tools and approaches will need to be effectively deployed at the national level, particularly as countries near elimination, plan for prevention of reintroduction, and transition away from donor assistance.

\section{Potential barriers to achieving malaria eradication}

Despite the excellent progress and numerous enabling factors, serious challenges to achieving eradication remain that could serve as barriers to success if not adequately addressed. For the 35 malaria-eliminating countries, the most significant dangers are a reduction of political commitment and an associated decline 
in financing to finish the job and prevent reintroduction of malaria over time. These two factors-waning political commitment and declining budgets, particularly in the face of competing health priorities-have historically been associated with massive malaria resurgences, several of which occurred in countries that are once again attempting to eliminate. ${ }^{57,58}$ While the many declarations from national, regional, and global stakeholders to eliminate and eradicate malaria are promising, if political and financial commitment is not sustained, the goals will not be met. Further, failing to meet these goals will likely lead to disillusionment and undermine global progress and the prospects of eradication, mirroring the attitudes of the post-GMEP era. ${ }^{59}$ A World Health Assembly commitment to achieving eradication will play an essential role in maintaining focus and momentum toward this ambitious goal. In addition, as the global community begins to shape the eradication agenda, a significant degree of country-level engagement and ownership over the process is key for ensuring national political support and buy-in.

According to recent modeling work, an estimated US\$8.5 billion will be needed over the next fifteen years to adequately support the 35 malaria-eliminating countries in their efforts to achieve elimination and prevent reintroduction of malaria. ${ }^{24}$ Largely responsible for funding tools that enabled the global declines in malaria incidence, external aid allocations have been waning in the past few years as a result of the global financial crisis. Multilateral and bilateral donor funds have trended toward supporting low income, high malaria burden countries. Thus, a growing number of eliminating countries are "graduating” away from donor support. The 35 malaria-eliminating countries are projected to receive a 21 percent decrease in funding under the Global Fund's new funding model—a serious shortfall at a time when maintaining their gains and advancing the elimination agenda are essential. ${ }^{60}$ At the same time, while the national governments of the 35 countries provide nearly 80 percent of funding for elimination efforts, domestic malaria budgets are often diverted toward more pressing disease priorities that are perceived as a greater threat to public health. ${ }^{61}$

Identifying new and innovative funding streams and advocating governments to maintain political support for malaria elimination are crucial to ensure successful achievement of eradication. Recent examples of promising new funding sources for elimination and eradication include the Regional Malaria and Other Communicable Disease Threats Trust Fund administered by the Asian Development Bank for malariaendemic countries in the Asia Pacific; the Ross Fund, a joint partnership between the Government of the United Kingdom and the Bill \& Melinda Gates Foundation to fund global malaria research and development; and the Lives and Livelihoods Fund, a partnership between the Islamic Development Bank and the Bill \& Melinda Gates Foundation targeted toward Muslim countries to address a range of health and development issues, including malaria. ${ }^{62,63,64}$

Other significant challenges to achieving eradication are technical in nature, including growing drug and insecticide resistance, limited treatment options for $P$. vivax, and the increasing number of $P$. knowlesi infections in the Asia Pacific region. The research and development pipeline for new malaria insecticides, drugs, and diagnostics is robust and will receive additional financial support through the Ross Fund, but new products will likely not be available for several years. ${ }^{18,63}$ Identifying an optimal mix of interventions, improving intervention targeting, and eliminating local reservoirs of drug resistant parasites may help slow the spread of insecticide and drug resistance in the meantime. ${ }^{38,39}$ Successfully combatting $P$. vivax infections requires point-of-care diagnostics to detect glucose-6-phosphate dehydrogenase (G6PD) deficiency, a disorder that can lead to hemolytic anemia in patients treated with primaquine, the only effective drug against the dormant liver stage of P. vivax. G6PD detection kits are commercially 
available but not yet approved for use; drug alternatives to primaquine are under development. ${ }^{17,65}$ The emergence of human $P$. knowlesi infections in Southeast Asia poses a unique threat to eradication, in that simian malaria parasites are very difficult to distinguish from human species and misdiagnosis is rampant. As a result, the extent of the $P$. knowlesi burden and its transmission dynamics in human populations are largely unknown and effective surveillance and prevention methods cannot be put in place. In addition, a human malaria case caused by another simian parasite, $P$. cynomolgi, was recently detected in Malaysia, and is morphologically identical to $P$. vivax. Zoonotic malaria cases will likely continue to increase as urban development encroaches on the natural habitats of macaque monkeys, and new, more sensitive diagnostics will play a critical role in preventing further spread. ${ }^{66,67}$

\section{Discussion}

As global dialogue once again centers on malaria eradication and support for this ambitious goal grows, understanding the remarkable progress that has been made on a national and regional scale over the last fifteen years is key. While global focus on national malaria situations often centers on Africa, huge strides toward elimination have been made in other parts of the world, facilitated by expanding regional platforms that have provided much-needed political, financial, and technical support to participating countries. The progress made by countries in Asia Pacific, the Eastern Mediterranean, Europe, and Latin America must continue to be celebrated and their lessons and challenges propagated to inform and inspire continuing elimination efforts in these regions and in Africa.

Global malaria eradication must be driven at the country level and achieved collaboratively, region by region. Looking to the future, existing and new regional initiatives have considerable opportunity and room for growth. In the European region, a regional framework to prevent reintroduction and obtain malaria-free certification has been developed by WHO and member nations. ${ }^{28}$ The Organization of Islamic Cooperation and the Islamic Development Bank, in cooperation with RBM, recently called for increased political and financial commitment and collective action to control and eliminate malaria in Islamic countries in the Eastern Mediterranean and African regions, which account for more than half of the global malaria burden. ${ }^{68}$ In the Asia Pacific, APLMA has finalised its elimination roadmap and strategy to achieve the 2030 regional elimination goal, and a Malaria Elimination Dashboard is under development for the 22 countries in the region to measure and encourage progress. ${ }^{37}$ Formalized commitments to regional goals such as these will likely catalyze similar efforts on the national, regional, and global level.

When discussing global malaria goals and trends, it may be tempting to view the 35 malaria-eliminating countries as low priority compared to the high burden, low income countries where most malaria morbidity and mortality occurs. This is a serious misconception. The progress in eliminating countries is a major driver of global progress, and success in these countries is a critical step towards success in higher burden countries and, eventually, success in realizing a malaria-free world. Maintaining the momentum of the eliminating countries is essential, requiring sustained focus, political and financial support, rapid responses to challenges and setbacks, and constant recognition and celebration of progress. 


\section{Authors' contributions}

RGAF and AAP led the development of the manuscript concept. All authors contributed to the development of the manuscript outline and structure. GN conducted a literature search, drafted the first version of the manuscript, and generated the figures. All authors provided feedback and direction on the content and contributed to the drafting of the final version of the manuscript and figures.

\section{Declaration of interests}

All authors work at the Global Health Group of the University of California, San Francisco, CA, USA. The Global Health Group exists in part to support global, regional, and country efforts to achieve evidence-based malaria elimination. RGAF chairs the Malaria Elimination Group. RGAF co-chairs the Asia Pacific Malaria Elimination Network and the Global Health Group is the co-secretariat of the network. The findings and conclusions in this paper are those of the authors and do not necessarily represent the views of their employing organisations or of the sources of funding.

\section{Role of the funding source}

The authors are supported by the Malaria Elimination Initiative of the Global Health Group at the University of California, San Francisco, whose funding for this work comes from a grant from the Bill \& Melinda Gates Foundation. The funders had no role in the design or writing of this manuscript, or the decision to submit the manuscript for publication. The authors were not paid to write this manuscript.

The corresponding author had full access to all material included in the manuscript and had the final responsibility for the decision to submit for publication.

\section{Acknowledgements}

The authors would like to thank Alistair Dawson, Roly Gosling, Jimee Hwang, and Cara Smith Gueye of the UCSF Global Health Group for their review of the manuscript and helpful feedback. 


\section{References}

1. Bill \& Melinda Gates Foundation Press Room. Bill and Melinda Gates Call for New Global Commitment to Chart a Course for Malaria Eradication. GatesFoundation.org Media Center, 2007. Available from: http://www.gatesfoundation.org/Media-Center/Press-Releases/2007/10/Chart-aCourse-for-Malaria-Eradication/ (accessed 1 July 2015).

2. Roberts L, Enserink M. Did they really say... eradication? Science 2007; 318(5856):1544-5.

3. Feachem RGA, Phillips AA, Targett GA, eds. Shrinking the malaria map: a prospectus on malaria elimination. San Francisco: The Global Health Group, Global Health Sciences, University of California, San Francisco, 2009.

4. Feachem RGA, Phillips AA, Targett GA, Snow RW. Call to action: priorities for malaria elimination. Lancet 2010; 376(9752):1517-21.

5. Roll Back Malaria Partnership. The global malaria action plan: for a malaria free world. Geneva: World Health Organization; 2008. Available from: http://www.rollbackmalaria.org/microsites/gmap/ (accessed 17 December 2015).

6. Feachem RGA, Phillips AA, Hwang J, et al. Shrinking the malaria map: progress and prospects. Lancet 2010; 376(9752):1566-78.

7. World Health Organization Regional Office for Europe. The Tashkent Declaration: the move from malaria control to elimination in the WHO European Region. Copenhagen: WHO EURO; 2005. Available from: http://www.euro.who.int/_data/assets/pdf file/0004/98761/E87976.pdf?ua=1 (accessed 1 July 2015).

8. The Executive Board of Health Ministers' Gulf Cooperation Council. The Arabian Peninsula Free of Malaria Initiative. 2010. Available from: http://sgh.org.sa/enus/technicalprograms/infictiousdiseases/initiativearabianpeninsulafreeofmalaria.aspx (accessed 1 July 2015).

9. APMEN. About Us - Asia Pacific Malaria Elimination Network. 2015. Available from: http://apmen.org/about/ (accessed 1 July 2015).

10. Southern African Development Community. Malaria Elimination 8 (E8). SADC, 2012. Available from: https://tis.sadc.int/english/sarn/elimination-eight-e8/ (accessed 17 December 2015).

11. Global Malaria Programme. World Malaria Report 2014. Geneva: World Health Organization, 2014.

12. Liu J, Modrek S, Gosling RD, Feachem RGA. Malaria eradication: is it possible? Is it worth it? Should we do it? Lancet Glob Health 2013; 1(1):e2-3.

13. Gates B. We Can Eradicate Malaria-Within a Generation. GatesNotes, 2014. Available from: http://www.gatesnotes.com/Health/Eradicating-Malaria-in-a-Generation (accessed 1 July 2015).

14. Tatem AJ, Smith DL, Gething PW, Kabaria CW, Snow RW, Hay SI. Ranking of elimination feasibility between malaria-endemic countries. Lancet 2010; 376(9752):1579-91.

15. Moonen B, Cohen JM, Snow RW, et al. Operational strategies to achieve and maintain malaria elimination. Lancet 2010; 376(9752):1592-603. 
16. Sabot O, Cohen JM, Hsiang MS, et al. Costs and financial feasibility of malaria elimination. Lancet 2010; 376(9752):1604-15.

17. Cotter C, Sturrock HJ, Hsiang MS, et al. The changing epidemiology of malaria elimination: new strategies for new challenges. Lancet 2013; 382(9895):900-911.

18. Gates B, Chambers R. From Aspiration to Action: What Will It Take to End Malaria? 2015. Available from: http://endmalaria2040.org/ (accessed 28 September 2015).

19. Global Malaria Programme. Malaria elimination: a field manual for low and moderate endemic countries. Geneva: World Health Organization, 2007.

20. Organizacion Panamericana de la Salud. Paraguay inicia el camino hacia la certificacion de la eliminacion del Paludismo. 2014. Available from: http://www.paho.org/par/index.php?option=com content\&view=article\&id=1216:paraguay-inicia-elcamino-hacia-la-certificacion-de-la-eliminacion-del-paludismo\&Itemid=258 (accessed 1 July 2015).

21. Wickremasinghe R, Newby G. Maintaining zero: an update to the Sri Lanka malaria elimination case study. Sri Lanka Anti-Malaria Campaign and UCSF Global Health Group, 2014. Available from: http://globalhealthsciences.ucsf.edu/sites/default/files/content/ghg/mei-maintaining-zero-sri-lanka.pdf (accessed 8 July 2015).

22. World Health Organization Regional Office for Europe. Towards a malaria-free European Region by the end of 2015. Health topics: vector-borne and parasitic diseases, WHO EURO, 2015. Available from: http://www.euro.who.int/en/health-topics/communicable-diseases/vector-borne-and-parasiticdiseases/news/news/2015/04/towards-a-malaria-free-european-region-by-the-end-of-2015 (Accessed 1 July 2015).

23. Costa Rica Ministry of Health. 2014 Costa Rica Malaria Epidemiological Data. 2015.

24. Zelman B, Kiszewski A, Cotter C, Liu J. Costs of eliminating malaria and the impact of the global fund in 34 countries. PloS One 2014; 9(12):e115714.

25. Sturrock HJW, Roberts KW, Wegbreit J, Ohrt C, Gosling RD. Tackling imported malaria: an elimination endgame. Am J Trop Med Hyg 2015; 14-0256.

26. Tatem AJ, Smith DL. International population movements and regional Plasmodium falciparum malaria elimination strategies. Proc Natl Acad Sci 2010; 107(27):12222-7.

27. E8 Secretariat. Elimination 8 Concept Note. The Global Fund to Fight AIDS, Tuberculosis and Malaria, 2015. Available from: http://www.theglobalfund.org/en/portfolio/country/grant/?grant=QPA-M-E8S (accessed 17 December 2015).

28. Ejov M, Davidyants V, Zvantsov A. Regional framework for prevention of malaria reintroduction and certification of malaria elimination 2014-2020. Copenhagen: World Health Organization Regional Office for Europe, 2014. Available from: http://www.euro.who.int/_data/assets/pdf_file/0008/254978/Regional-framework-for-prevention-ofmalaria-reintroduction-and-certification-of-malaria-elimination-20142020.pdf (accessed 17 December 2015).

29. Gasimov E. Update on Malaria Elimination in WHO European Region [presentation]. WHO Malaria 
Policy Advisory Committee Meeting, Geneva. 16-18 September 2015. Available from: http://www.who.int/malaria/mpac/mpac-sept2015-euro-elimination-presentation.pdf?ua=1 (accessed 17 December 2015).

30. Coleman M, Al-Zahrani MH, Coleman M, et al. A country on the verge of malaria elimination - the Kingdom of Saudi Arabia. PLoS ONE 2014; 9(9):e105980.

31. Hsiang MS, Abeyasinghe R, Whittaker M, Feachem RGA. Malaria elimination in Asia-Pacific: an under-told story. Lancet 2010; 375(9726):1586-1587.

32. APMEN. Media release: APMEN announces Papua New Guinea as new Country Partner. Asia Pacific Malaria Elimination Network - News. 2015. Available from: http://apmen.org/news/2015/9/18/papua-new-guinea-joins-the-asia-pacific-malaria-elimination.html (accessed 18 September 2015).

33. Roll Back Malaria Partnership. The Asia Pacific Malaria Elimination Network (APMEN): Supporting the common goal of a malaria-free Asia Pacific. Geneva: World Health Organization, 2014. Available from: http://www.rollbackmalaria.org/files/files/resources/APMENP\%26I.pdf (accessed 17 December 2015).

34. Cao J, Sturrock HJW, Cotter C, et al. Communicating and monitoring surveillance and response activities for malaria elimination: China’s “1-3-7” strategy. PLoS Med 2014; 11(5):e1001642.

35. Asia Pacific Leaders Malaria Alliance. APLMA: United we defeat malaria in Asia and the Pacific. 2015. Available from: http://aplma.org/ (accessed 1 July 2015).

36. Asia Pacific Leaders Malaria Alliance. Task Force Progress Report 2014. Manila: APLMA, 2014. Available from: http://www.aplma.org/upload/resource/Reports/Task\%20Force\%20Report\%202014.pdf (accessed 17 December 2015).

37. Asia Pacific Leaders Malaria Alliance. APLMA Malaria Elimination Roadmap. 2015. Available from: http://aplma.org/blog/24/East-Asia-Summit-leaders-endorse-APLMA-Malaria-EliminationRoadmap/ (accessed 22 November 2015).

38. World Health Organization. Strategy for malaria elimination in the Greater Mekong Subregion (2015-2030). WHO Western Pacific Regional Office, 2015. Available from: http://www.who.int/malaria/areas/greater_mekong/national-strategies-plans/en/ (accessed 15 July 2015).

39. Smith Gueye C, Newby G, Hwang J, et al. The challenge of artemisinin resistance can only be met by eliminating Plasmodium falciparum malaria across the Greater Mekong subregion. Malar J 2014; 13(1):286.

40. Regional Steering Committee for the Regional Artemisinin Initiative. Regional Artemisinin Initiative Concept Note. The Global Fund to Fight AIDS, Tuberculosis and Malaria, 2013. Available from: www.theglobalfund.org/ProgramDocuments/QMU/ConceptNotes/2013/QMUM_ConceptNote_0_en/ (accessed 27 Aug 2015).

41. E8 Secretariat. Elimination 8 Strategic Plan 2015-2020. 2015. 
42. Office of the UN Secretary-General's Special Envoy for Financing the Health Millennium Development Goals and for Malaria. African Leaders Call for Elimination of Malaria by 2030. MDG Health Envoy-News, 2015. Available from: http://www.mdghealthenvoy.org/african-leaders-call-forelimination-of-malaria-by-2030/ (accessed 3 Aug 2015).

43. The Global Fund to Fight AIDS, Tuberculosis and Malaria. Ten Countries Rally to Eliminate Malaria in Central America and the Caribbean. The Global Fund Media Center, 2013. Available from: http://www.theglobalfund.org/en/mediacenter/newsreleases/2013-06-

28_Ten_Countries_Rally_to_Eliminate_Malaria_in_Central_America_and_the_Caribbean/(accessed 1 July 2015).

44. Herrera S, Ochoa-Orozco SA, González IJ, Peinado L, Quiñones ML, Arévalo-Herrera M. Prospects for malaria elimination in Mesoamerica and Hispaniola. PLoS Negl Trop Dis 2015; 9(5):e0003700.

45. CDC Foundation. Consortium Aims to Eliminate Malaria on Hispaniola by 2020 Starting With $\$ 29.9$ Million Grant to CDC Foundation. 2015. Available from: http://www.cdcfoundation.org/pr/2015/gatesfoundation-grant-to-cdcfoundation-aims-to-eliminatemalaria-hispaniola (accessed 1 July 2015).

46. CDC Foundation. Malaria Zero: The Alliance for a Malaria-Free Haiti. 2015. Available from: http://www.cdcfoundation.org/malariazero (accessed 17 December 2015).

47. Roll Back Malaria Partnership. Action and investment to defeat malaria 2016-2030: for a malariafree world. Geneva: World Health Organization on behalf of the Roll Back Malaria Partnership Secretariat, 2015. Available from: http://www.rollbackmalaria.org/about/about-rbm/aim-2016-2030 (accessed 29 June 2015).

48. World Health Organization. Global Technical Strategy for Malaria 2016-2030. Geneva: WHO, 2015. Available from: http://www.who.int/malaria/publications/atoz/9789241564991/en/ (accessed 29 June 2015).

49. Gosling J, Case P, Tulloch J, et al. Effective Program Management: A Cornerstone of Malaria Elimination. Am J Trop Med Hyg 2015; 14-0255.

50. Alonso PL, Brown G, Arevalo-Herrera M, et al. A Research Agenda to Underpin Malaria Eradication. PLoS Med 2011; 8(1): e1000406.

51. Malaria Eradication Scientific Alliance (MESA). About Us. 2015. Available from: http://www.malariaeradication.org/about-us (accessed 19 December 2015).

52. Kelly GC, Tanner M, Vallely A, Clements A. Malaria elimination: moving forward with spatial decision support systems. Trends Parasitol 2012; 28(7):297-304.

53. Ohrt C, Roberts KW, Sturrock HJW, Wegbreit J, Lee BY, Gosling RD. Information systems to support surveillance for malaria elimination. Am J Trop Med Hyg 2015; 14-0257.

54. World Health Organization Regional hub for the Greater Mekong Subregion. Migrant and mobile population (MMP) toolkits. SEARO; 2015. Available from:

http://www.who.int/malaria/areas/greater_mekong/toolkits/en/ (accessed 17 December 2015). 
55. Koita K, Novotny J, Kunene S, et al. Targeting imported malaria through social networks: a potential strategy for malaria elimination in Swaziland. Malar J 2013; 12(1):219.

56. Whittaker MA, Dean AJ, Chancellor A. Advocating for malaria elimination - learning from the successes of other infectious disease elimination programmes. Malar J 2014; 13:221

57. Cohen JM, Smith DL, Cotter C, et al. Malaria resurgence: a systematic review and assessment of its causes. Malar J 2012; 11(1):122.

58. Danis K, Lenglet A, Tseroni M, Baka A, Tsiodras S, Bonovas S. Malaria in Greece: Historical and current reflections on a re-emerging vector borne disease. Travel Med Infect Dis 2013; 11(1): 8-14.

59. Nájera JA, González-Silva M, Alonso PL. Some lessons for the future from the Global Malaria Eradication Programme (1955-1969). PLoS Med 2011; 8(1):e1000412.

60. Zelman B, Melgar M, Larson E, Phillips A, Shretta R. Impact of the Global Fund's New Funding Model on 34 malaria-eliminating countries (under review). Malar J 2016.

61. Kumar K, Pigazzini A, Stenson B. Financing for malaria elimination. Cambridge Economic Policy Associates, 2013. Available from:

http://globalhealthsciences.ucsf.edu/sites/default/files/content/ghg/mei-financing-malariaelimination.pdf (accessed 28 Aug 2015).

62. Asian Development Bank. News release: Australia commits US\$16 Million for Asia-Pacific Fight against Malaria. Manila: ADB; 2014. Available from: http://www.adb.org/news/australia-commitsus16-million-asia-pacific-fight-against-malaria (accessed 17 December 2015).

63. HM Treasury, Department for International Development, The Rt Hon Justine Greening MP and The Rt Hon George Osborne MP. News story: Chancellor George Osborne and Bill Gates to join forces to end malaria. Gov.UK; 2015. Available from: https://www.gov.uk/government/news/chancellorgeorge-osborne-and-bill-gates-to-join-forces-to-end-malaria (accessed 17 December 2015).

64. Bill \& Melinda Gates Foundation. Where We Work, Middle East Office: The Lives and Livelihoods Fund. Available from: http://www.gatesfoundation.org/Where-We-Work/Middle-East-Office/Livesand-Livelihoods-Fund (accessed 18 December 2015).

65. Baird JK. Point-of-care G6PD diagnostics for Plasmodium vivax malaria is a clinical and public health emergency. BMC Med 2015; 13(1): 296.

66. Moyes CL, Henry AJ, Golding N, et al. Defining the Geographical Range of the Plasmodium knowlesi Reservoir. PLoS Negl Trop Dis 2014: 8(3): e2780.

67. Ta TH, Hisam S, Lanza M, Jiram AI, Ismail N, Rubio JM. First case of a naturally acquired human infection with Plasmodium cynomolgi. Malar J 2014; 13:68.

68. Roll Back Malaria Partnership. Member states of the Organization of Islamic Cooperation (OIC) committed to strong action against malaria. Jeddah, KSA: Islamic Development Bank, The Organization of Islamic Cooperation, and Roll Back Malaria Partnership, 2015. Available from: http://www.rollbackmalaria.org/files/files/latest_news/PRESS\%20RELEASE\%20\%20WMD\%202015\%20OIC\%20_FINAL\%20EN.pdf (accessed 8 July 2015). 


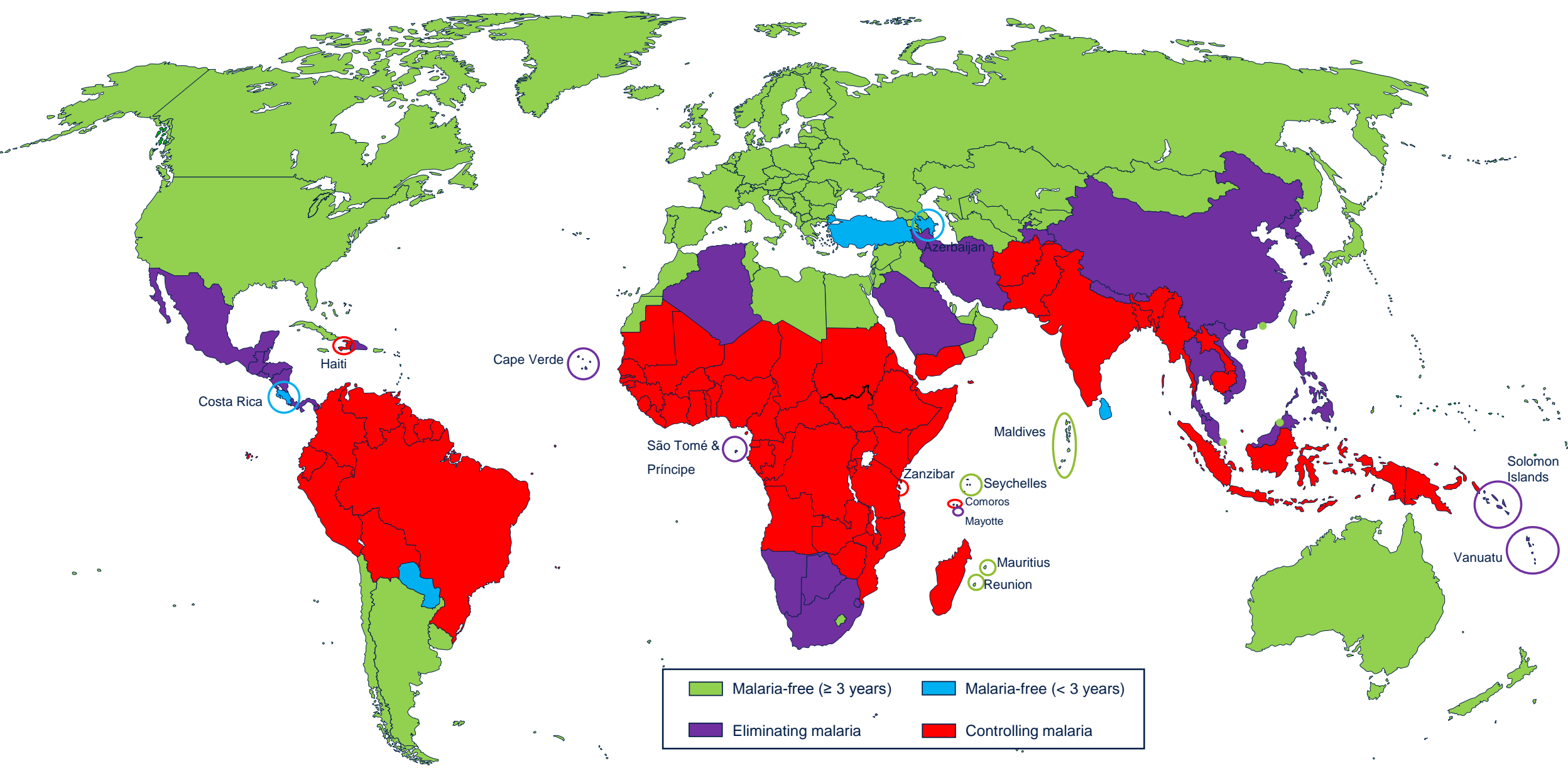

Caption: The list of eliminating countries is evaluated annually using data collected from WHO's World Malaria Report; national malaria program reports, elimination strategies, and operational plans; reports and updates from partner organizations and stakeholders; and other resources. When countries are certified by the WHO as malaria-free, or when they report three consecutive years of zero locally transmitted cases in World Malaria Report, they are removed from the eliminating country list. 
Figure 2: Combined reported cases and deaths for the 35 malaria-eliminating countries, 2000-2013*

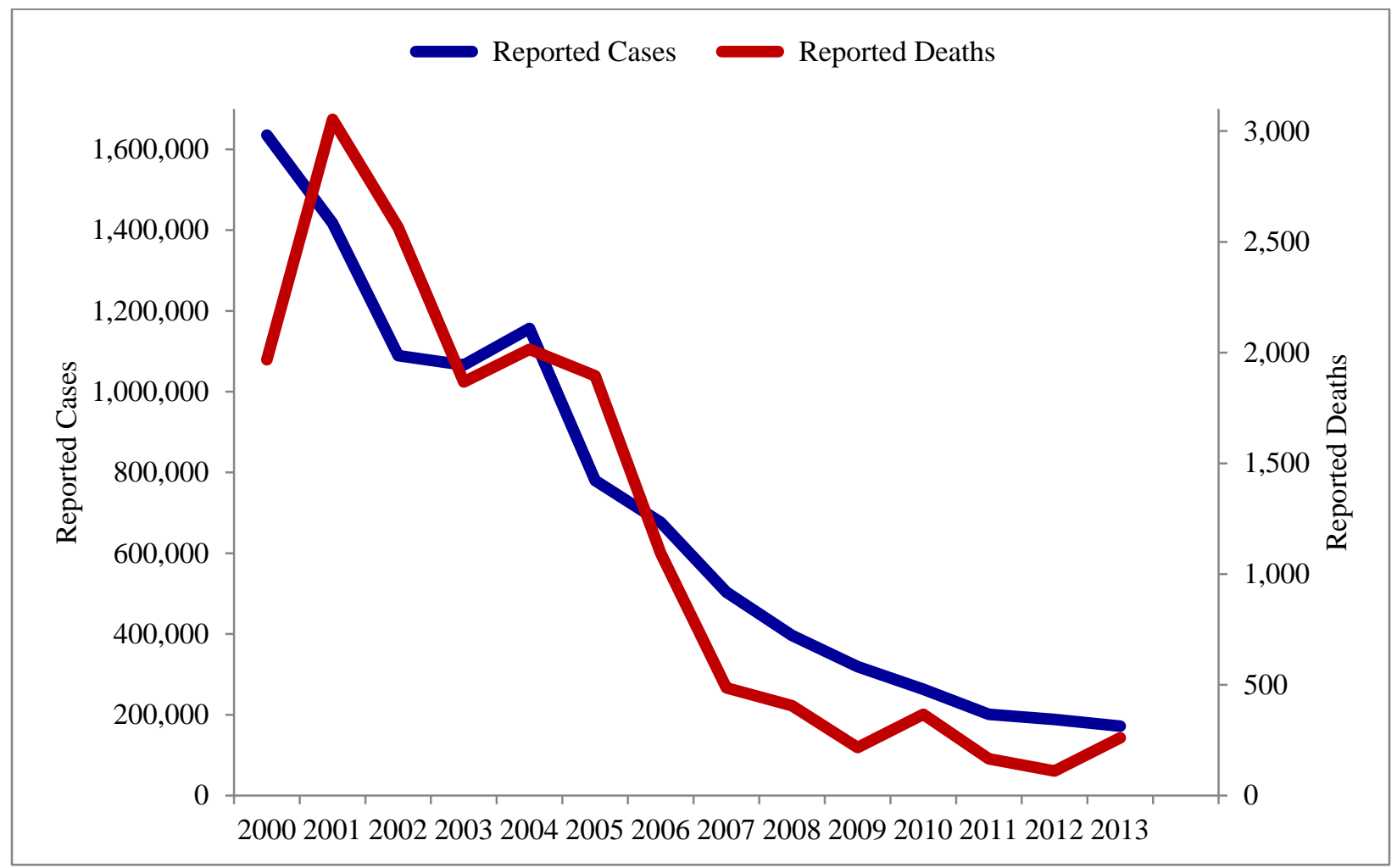

Caption: From 2000 to 2013, the 35 malaria-eliminating countries reported a 90 percent decline in cases and 87 percent decline in deaths due to malaria. In comparison, during the same period global malaria morbidity and mortality declined by 30 percent and 47 percent, respectively.

*Data is sourced from World Malaria Report 2014 and national malaria program reports. The definition of 'reported cases' varies by year and by country: if countries distinguish between locally-transmitted cases and imported cases when reporting, only those that were locally-transmitted are represented in the graph; the countries that do make this distinction began reporting imported cases in different years; the following countries did not distinguish between locally-transmitted and imported in reports between 2000 and 2013: Botswana, Democratic People's Republic of Korea, Guatemala, Honduras, Namibia, Nepal, Nicaragua, Panama, Philippines, Sao Tome \& Principe, Solomon Islands, South Africa, Thailand, Vanuatu, Vietnam; the following countries did not report data on deaths in 2000: Botswana, Cape Verde, DPR Korea, Mayotte, Namibia, Nepal, Saudia Arabia, Swaziland, Tajikistan. 
Figure 3: 35 malaria-eliminating country case trend graphs, 2000-2013

\section{Algeria}

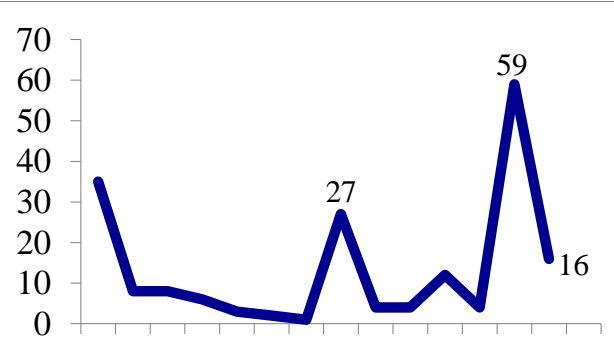

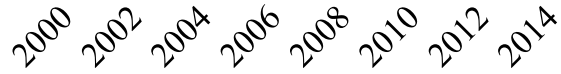

\section{Bhutan}
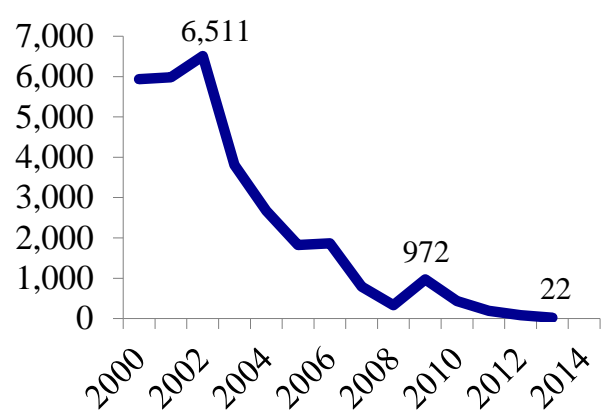

\section{China}

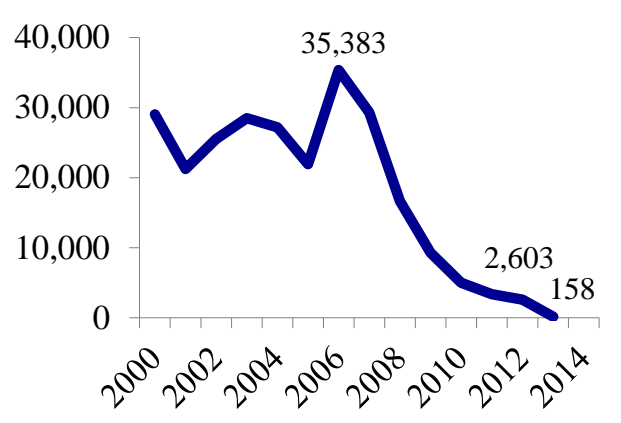

\section{DPR Korea}

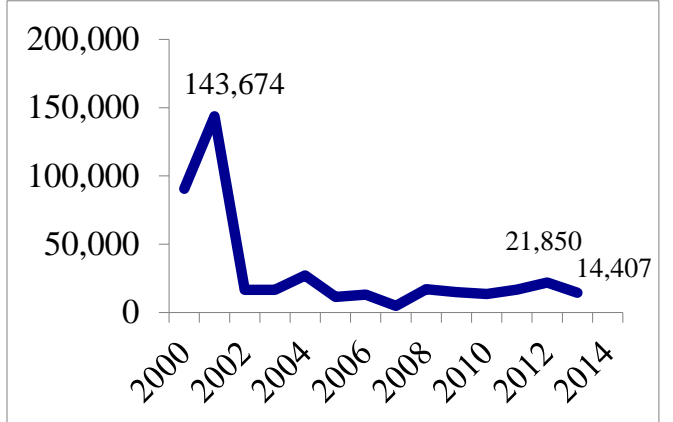

\section{Azerbaijan}

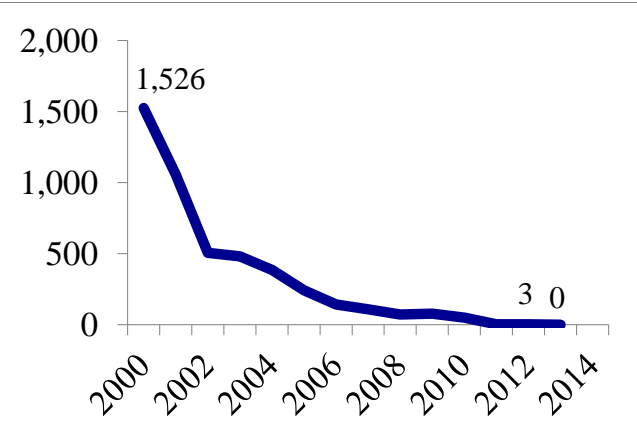

\section{Botswana}

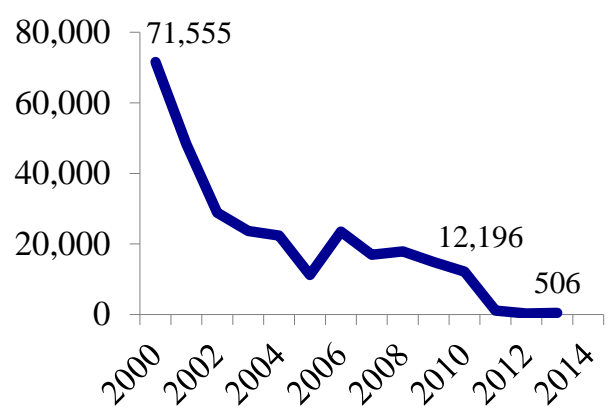

\section{Costa Rica}

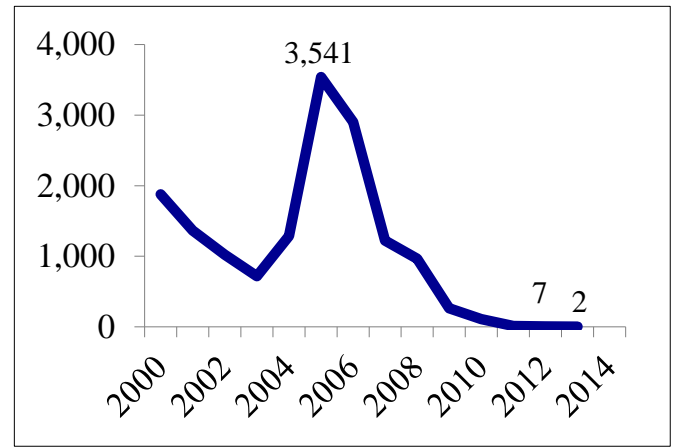

\section{El Salvador}

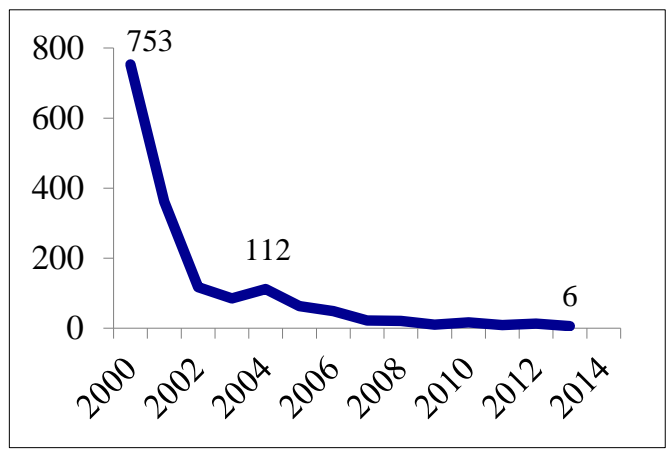

\section{Belize}

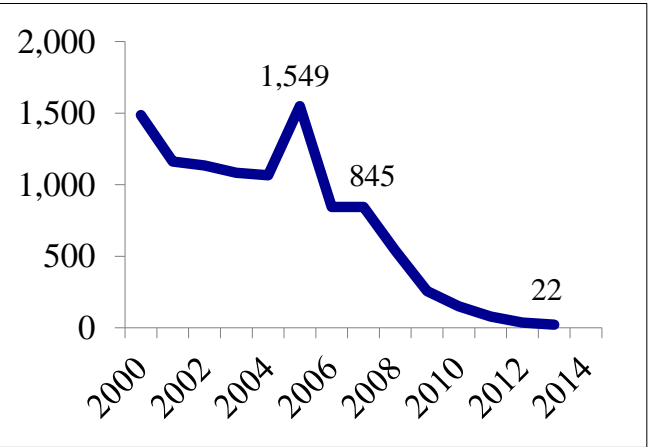

\section{Cape Verde}

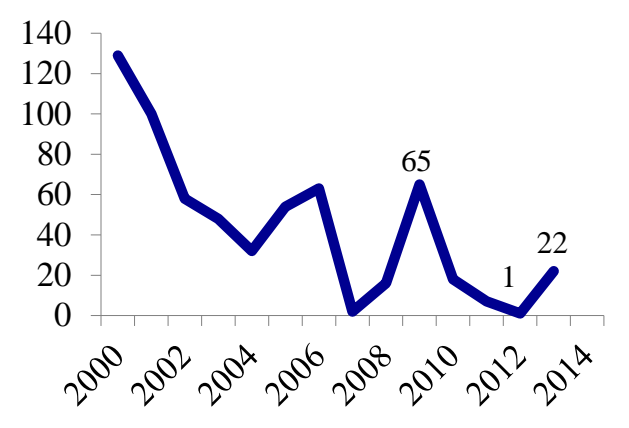

\section{Dominican Republic}

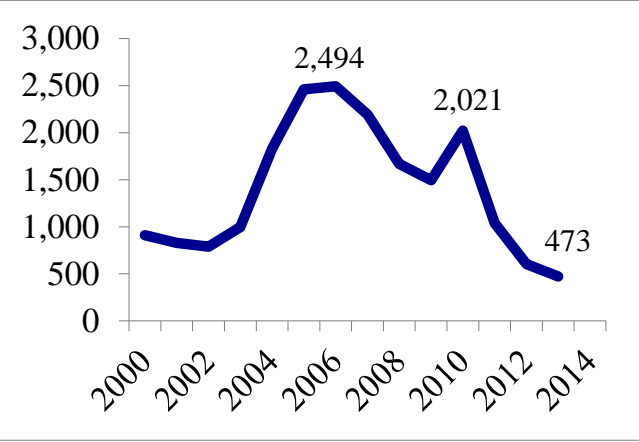

\section{Guatemala}

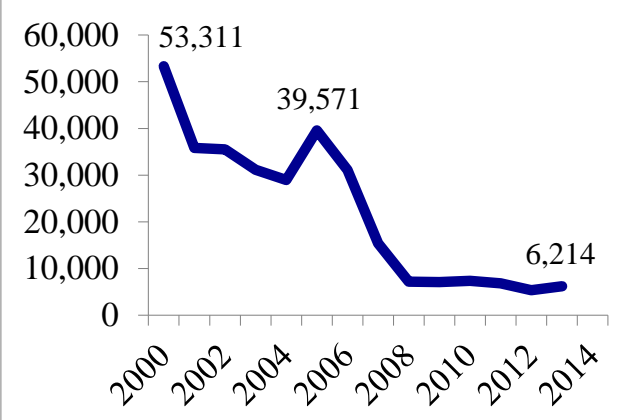


Figure 3: 35 malaria-eliminating country case trend graphs, 2000-2013

\section{Honduras}

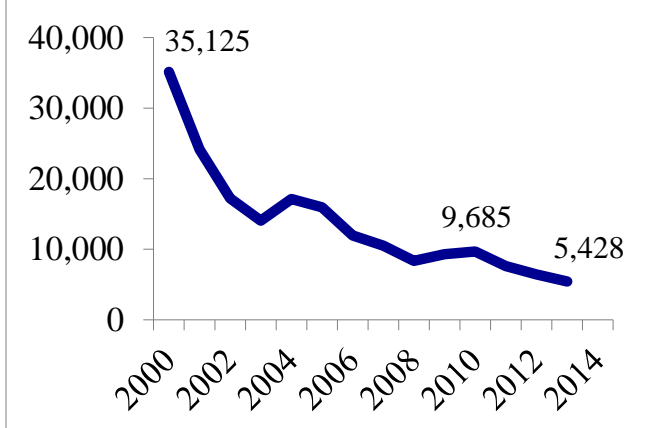

\section{Mayotte}

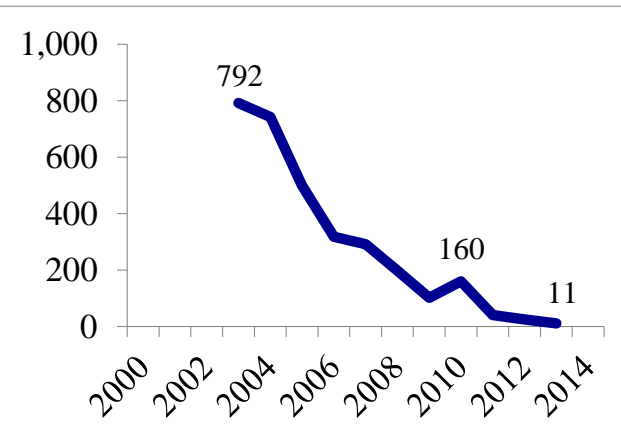

\section{Nepal}

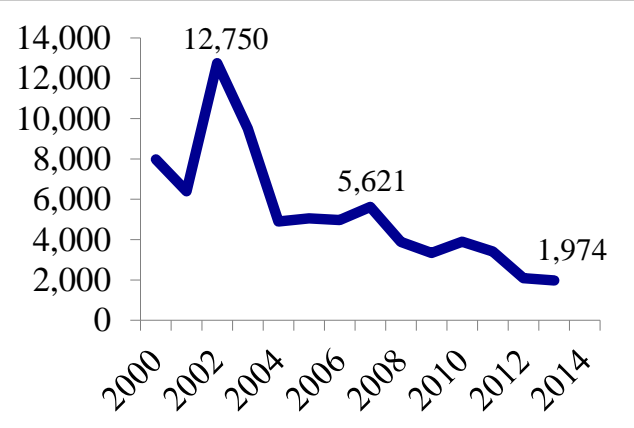

\section{Paraguay}

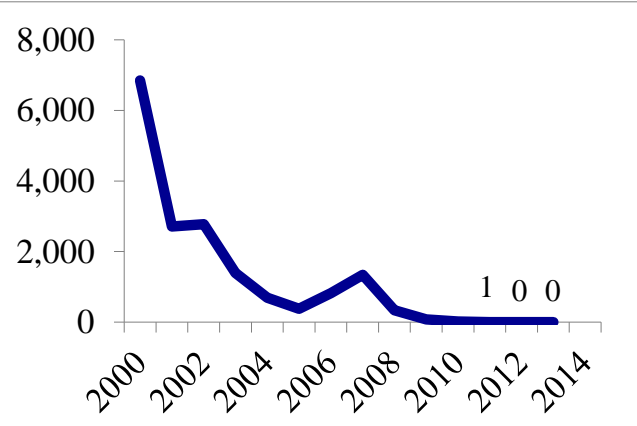

Iran

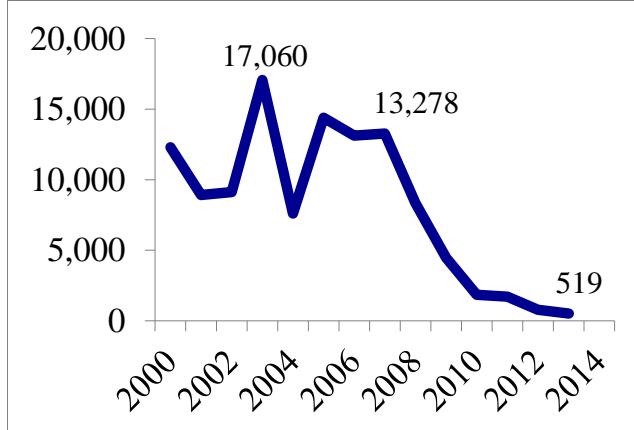

Mexico

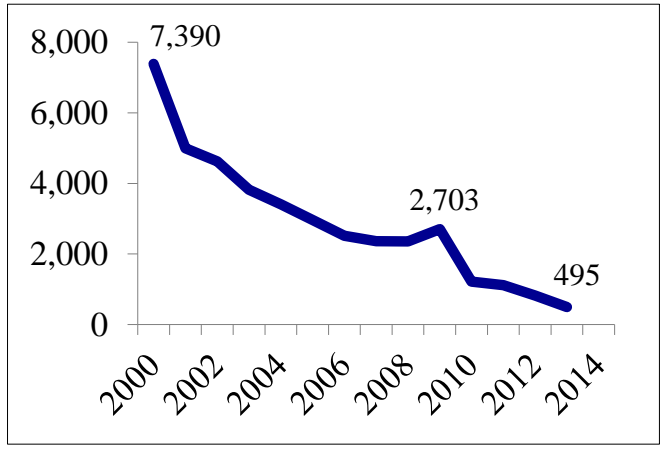

Nicaragua

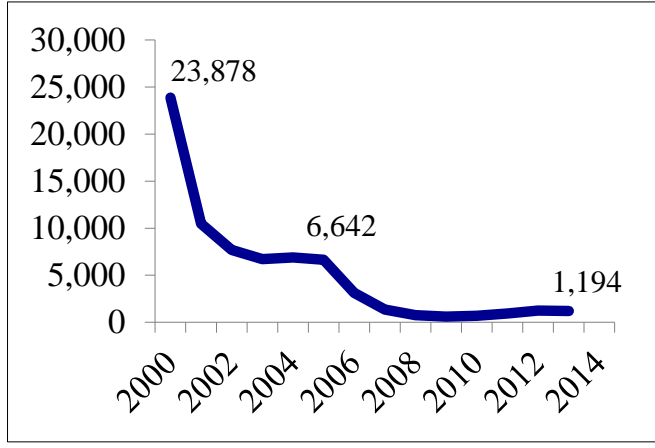

\section{Philippines}

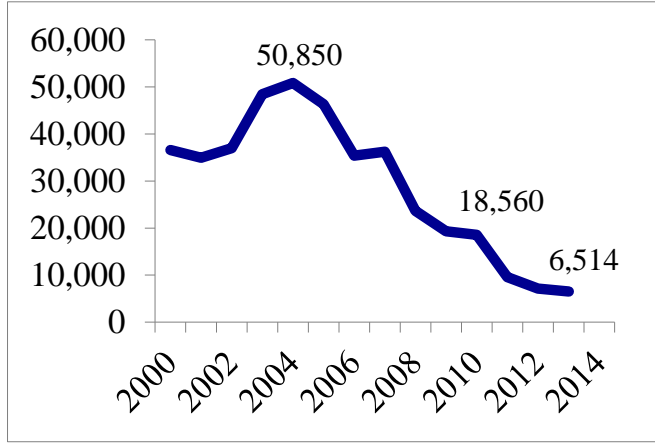

Malaysia

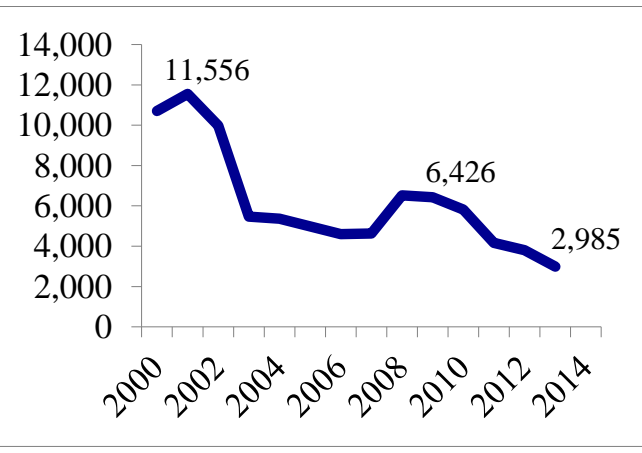

\section{Namibia}

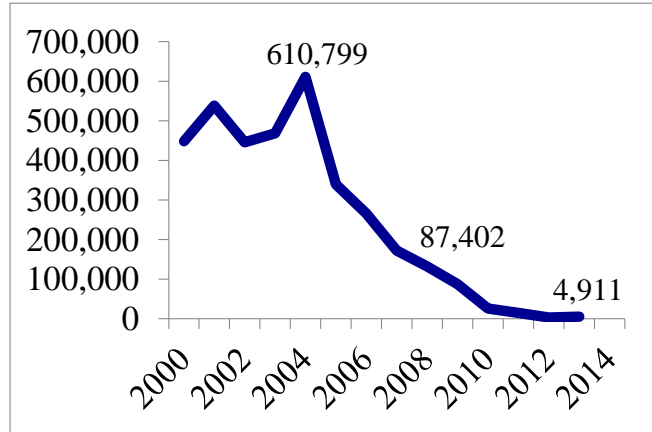

\section{Panama}

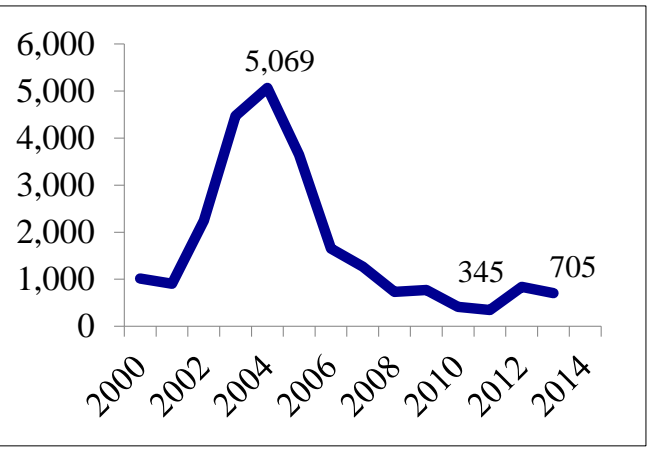

\section{Republic of Korea}

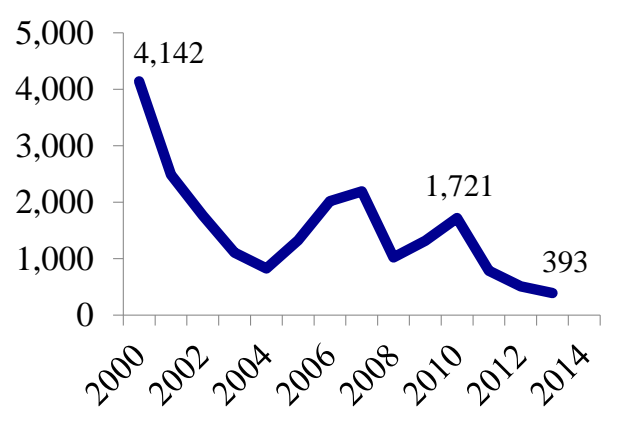


Figure 3: 35 malaria-eliminating country case trend graphs, 2000-2013

\section{Sao Tome \& Principe}

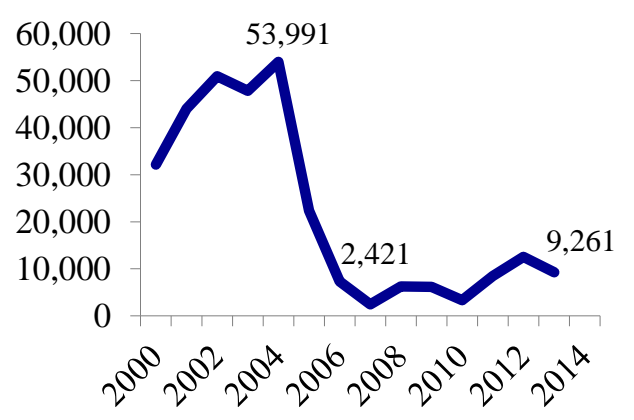

\section{South Africa}

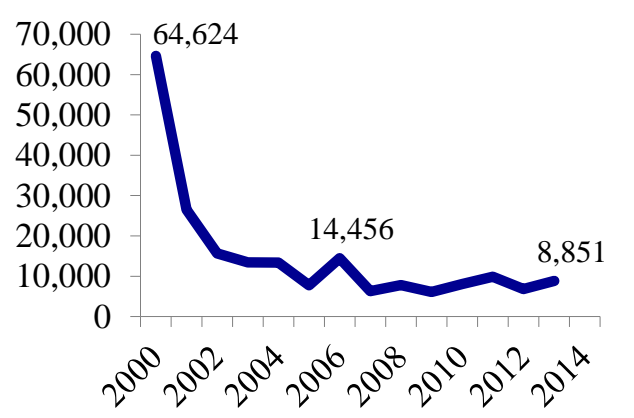

\section{Tajikistan}

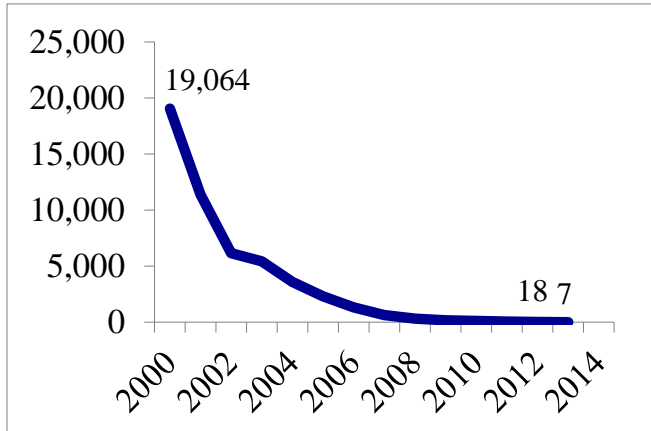

\section{Vanuatu}

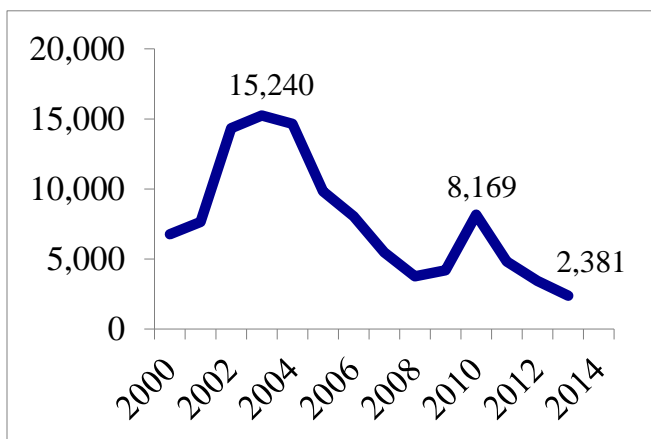

\section{Saudi Arabia}

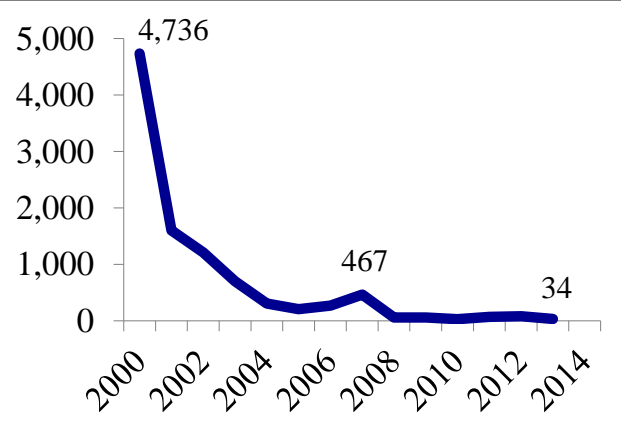

\section{Sri Lanka}

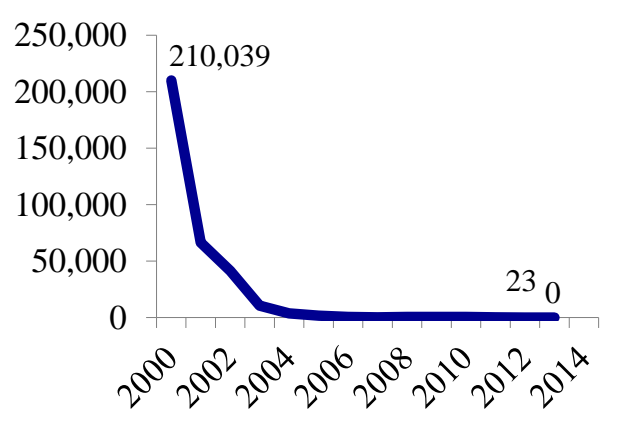

\section{Thailand}

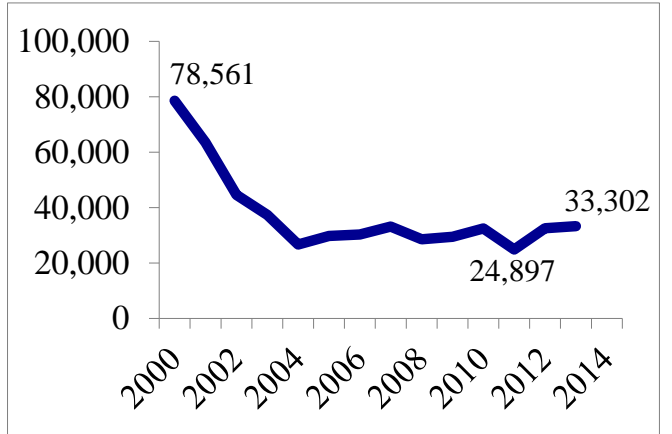

\section{Vietnam}

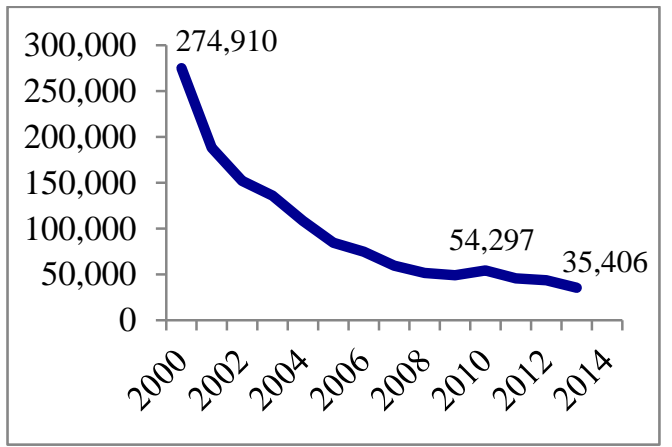

\section{Solomon Islands}

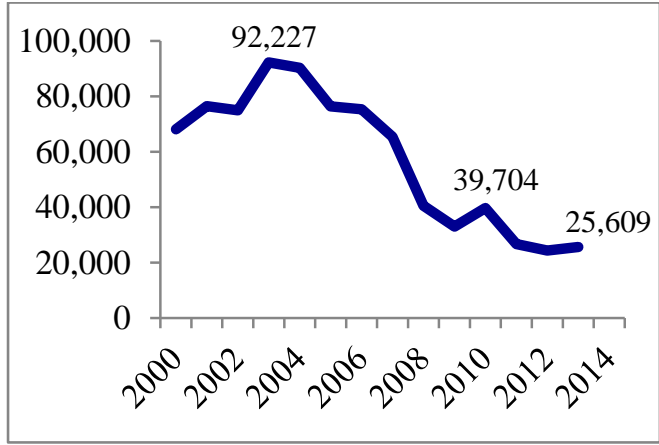

\section{Swaziland}

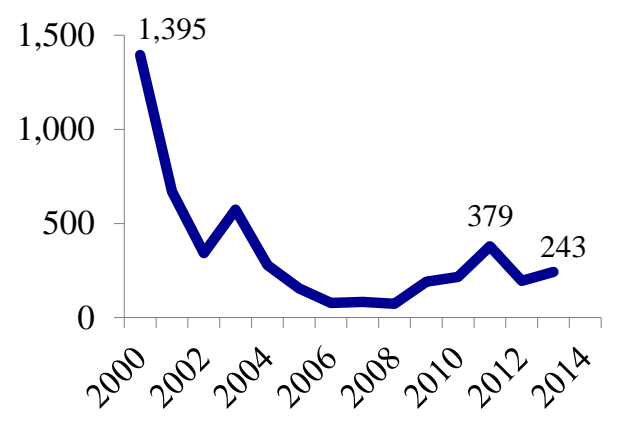

Turkey

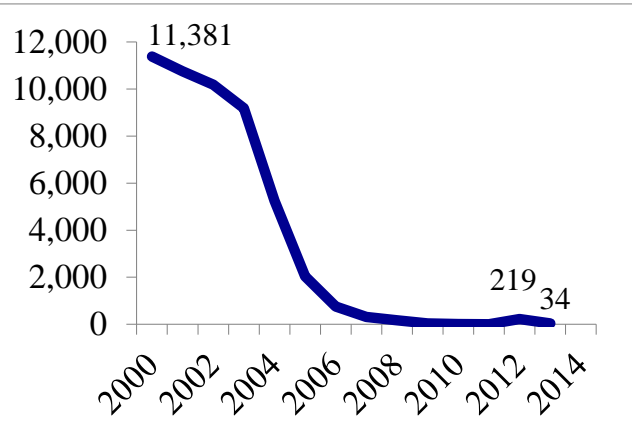




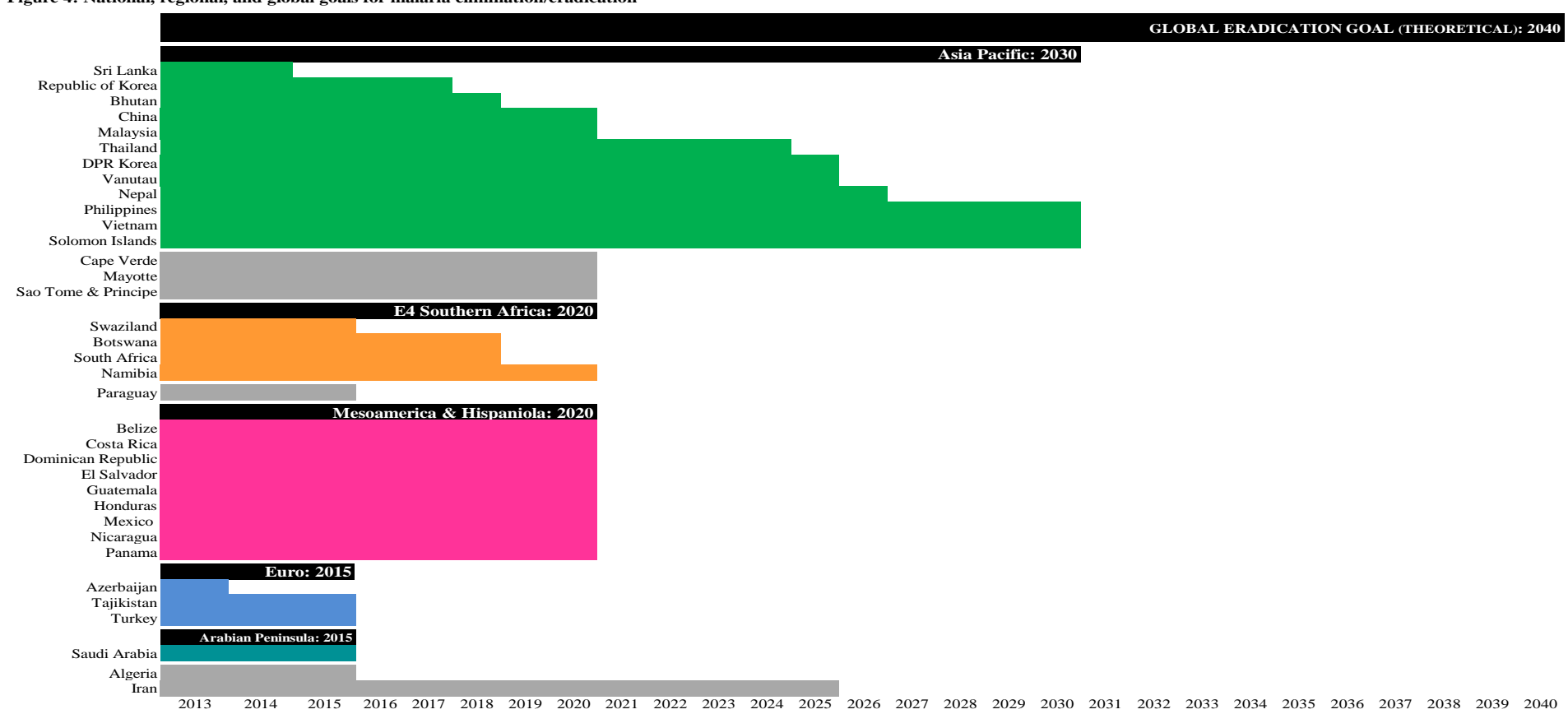
*Countries represented by grey lines are those that have national elimination goals only; black lines represent global and regional goals; the elimination goal for Solomon Islands is represented as 2030 in keeping with the goal set for Asia Pacific, however, the country has not yet revised its 2035 national goal to align with the more aggressive regional goal 


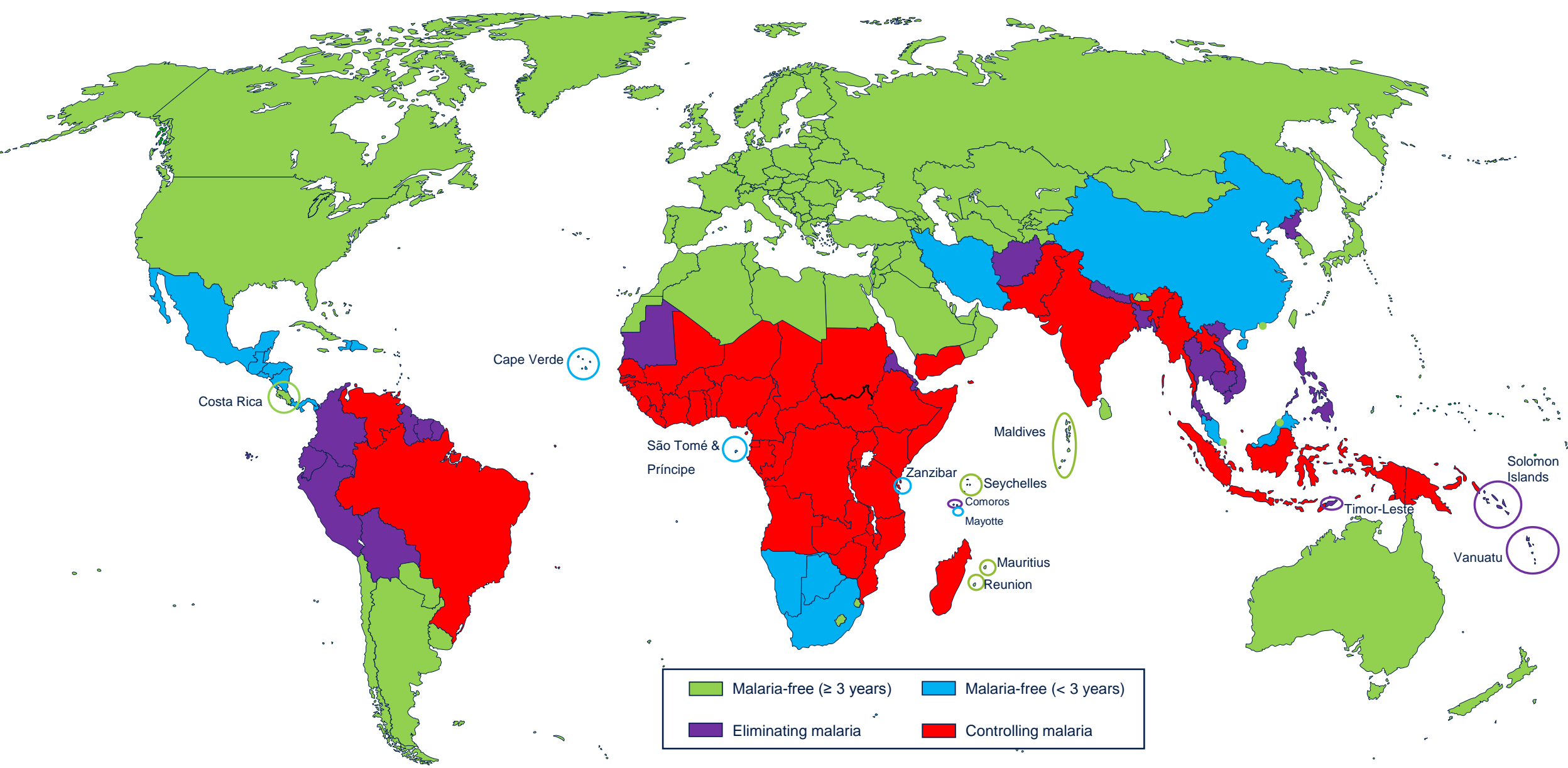

Caption: Elimination date projections are based on current national and regional goals as well as epidemiological progress as documented in WHO's annual World Malaria Report. For those countries that do not currently have clearly defined national or regional goals, elimination dates have been projected based on documented country-level efforts to reach pre-elimination status, recent epidemiological trends, geographical settings such as islands, and the necessary degree of ambition and optimism essential to achieve global eradication within a generation. 


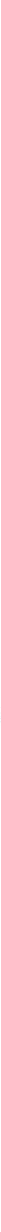

Caption: Elimination date projections are based on current national and regional goals as well as epidemiological progress as documented in WHO's annual World Malaria Report. For those countries that do not currently have clearly defined national or regional goals, elimination dates have been projected based on documented country-level efforts to reach pre-elimination status, recent epidemiological trends, geographical settings such as islands, and the necessary degree of ambition and optimism essential to achieve global eradication within a generation. 